\title{
A Disasters and Elections: Estimating the Net Effect of Damage and Relief in Historical Perspective
}

\author{
Boris Heersink ${ }^{1}$, Brenton D. Peterson ${ }^{1,2}$ and \\ Jeffery A. Jenkins ${ }^{1}$
}

\author{
${ }^{1}$ Department of Politics, University of Virginia, Charlottesville, VA 22904, United States. Email: heersink@viriginia.edu, \\ jajenkins@virginia.edu \\ ${ }^{2}$ School of Finance and Applied Economics, Strathmore University, Nairobi, Kenya. Email: brenton.peterson@virginia.edu
}

\begin{abstract}
Do natural disasters help or hurt politicians' electoral fortunes? Research on this question has produced conflicting results. Achen and Bartels $(2002,2016)$ find that voters punish incumbent politicians indiscriminately after such disasters. Other studies find that voters incorporate the quality of relief efforts by elected officials. We argue that results in this literature may be driven, in part, by a focus on contemporary cases of disaster and relief. In contrast, we study a case of catastrophic flooding in the American South in 1927, in which disaster aid was broadly and fairly distributed and Herbert Hoover (the 1928 Republican presidential candidate) was personally responsible for overseeing the relief efforts. Despite the distribution of unprecedented levels of disaster aid, we find that voters punished Hoover at the polls: in affected counties, Hoover's vote share decreased by more than 10 percentage points. Our results are robust to the use of synthetic control methods and suggest that-even if voters distinguish between low- and high-quality responses-the aggregate effect of this disaster remains broadly negative. Our findings provide some support for Achen and Bartels' idea of blind retrospection, but also generate questions about the precise mechanisms by which damage and relief affect vote choice.
\end{abstract}

\section{Introduction}

Studies on the electoral consequences of natural disasters have examined whether voters issue blanket electoral punishment to incumbent politicians in the wake of such disasters, or whether they assess the response of incumbents and reward or punish based on the quality of relief efforts. Studying natural disasters-random events that are exogenous to actions taken by elected officials-is valuable because it provides insight into the logic (or lack thereof) behind retrospective voting. ${ }^{1}$ That is, if voters punish politicians for the effects of random events without incorporating those officials' responses, the accountability mechanism of elections is weakened.

Studies of the effects of disaster and relief have come to contradictory conclusions. Achen and Bartels (2002, 2016) established a foundation for the study of "blind retrospection" by investigating the electoral consequences of shark attacks along the New Jersey shore in 1916, droughts and floods in twenty-six presidential elections across the 20th century, and droughts and floods in the 2000 presidential election. Across these cases, they find evidence that citizens punish incumbent party candidates for random events outside of their control.

In contrast, other research suggests that voters represent an "attentive electorate", capable of assigning praise and blame after a natural disaster by incorporating not just the effects of disasters

Published

3 April 2017

Corresponding author Jeffery A. Jenkins

Edited by

Jens Hainmueller

(C) The Author(s) 2017. Published by Cambridge University Press on behalf of the Society for Political Methodology.

Authors' note: We thank Alex Theodoridis, Adam Slez, and anonymous reviewers for their comments. A previous version of this paper was presented at the 2016 annual meeting of the Midwest Political Science Association in Chicago. Full replication materials are archived online: Heersink, Boris; Peterson, Brenton D.; Jenkins, Jeffery A., 2016, "Disasters and Elections: Estimating the Net Effect of Damage and Relief in Historical Perspective", doi:10.7910/DVN/AKHHHF, Harvard Dataverse, UNF:6:bcCeuvD3haeNx4alZXnrWw==.

1 Retrospective voting is a backward looking assessment of elected politicians' performance in office. That is, politicians are typically judged by the votes they cast and parties by the policies they adopt. However, parties are also evaluated for events beyond their control. For example, the president's party in Congress is often rewarded or punished based on macroeconomic conditions beyond distinct political control (Tufte 1978). 
but also subsequent relief operations. Healy and Malhotra (2009) find no evidence that disaster damage influences presidential vote share but do uncover a relationship between relief spending and support for the incumbent party. Similarly, Healy and Malhotra (2010) and Gasper and Reeves (2011) find voters punish incumbent presidents for damage from severe weather but that positive electoral effects of disaster declarations overwhelm the negative effects of the disaster itself. A key difference between these findings relates to the inclusion of relief spending as a variable: studies that account for relief efforts generally find that voters balance their assessment of disaster and subsequent relief.

Whether and how voters respond to disaster relief, however, is likely to be a product of their expectations regarding how the state should respond, a perspective that should vary across time and space. ${ }^{2}$ For example, voters who live in a country with a highly active government will have different expectations regarding government relief than voters who live in a country with a less active government. These expectations are likely to depend on voters' understanding of the state's role at the time of the disaster.

Studies that assess the attentive electorate have covered differentiation across "space"-that is, across countries in the modern political era. In addition to studies that focus on the United States, a considerable literature also examines natural disaster and relief operations in other countries (Bechtel and Hainmueller 2011; Cole et al. 2012; Fair et al. 2013; Gallego 2012). These comparative studies find that voters incorporate government relief in their response to natural disasters and that, in at least some cases, natural disasters can be an electoral boon to incumbent politicians.

Differentiation across time, however, has not been studied to the same extent. While Achen and Bartels study some cases in the pre-New Deal United States (such as the 1916 shark attacks), research that examines attentive retrospection has focused exclusively on the post-New Deal era. This is concerning because, as the federal government has expanded dramatically over time, it has likely shaped voters' perception of what the government should do, adjusting citizen expectations of state action. While the federal government has always been involved in (disaster) relief in some form (Dauber 2013), national politicians in the pre-New Deal era generally agreed that relief of hardship was the responsibility of state and local governments (Sundquist 1983). ${ }^{3}$ Thus, while voters in the post-New Deal era may have come to expect the federal government to provide aid in response to disasters, the same may not be true for voters in the early 20th century. To the extent that voters held different expectations in the pre-New Deal era, they may have held elected officials to different standards as well.

We contribute to this fast-growing literature by estimating the net electoral effect of disaster and relief in a single case of catastrophic flooding: the 1927 Mississippi Flood. This case is particularly interesting because (a) relief was provided on a then unprecedented scale and (b) 1928 Republican presidential candidate Herbert Hoover was responsible for the distribution of aid. Using county-level data on the severity of damage and the extent of the government's response and both difference-in-differences and synthetic control models, we estimate the effect of a disaster that was-by most measures-the most damaging river flood in US history. Contrary to studies that find support for the attentive retrospection hypothesis, we find that the flood cost Hoover 10.8 percentage points in affected counties, despite his close association with the relief efforts.

2 Other moderators of the relationship between natural disasters and vote choice are also likely to vary over time. As Abney and Hill found in the context of Hurricane Betsy in 1965, many voters did not think politicians should be held responsible for "acts of god" at all (Abney and Hill 1966).

3 This was also the position held by FDR during the 1932 presidential campaign (Sundquist 1983, 208). 


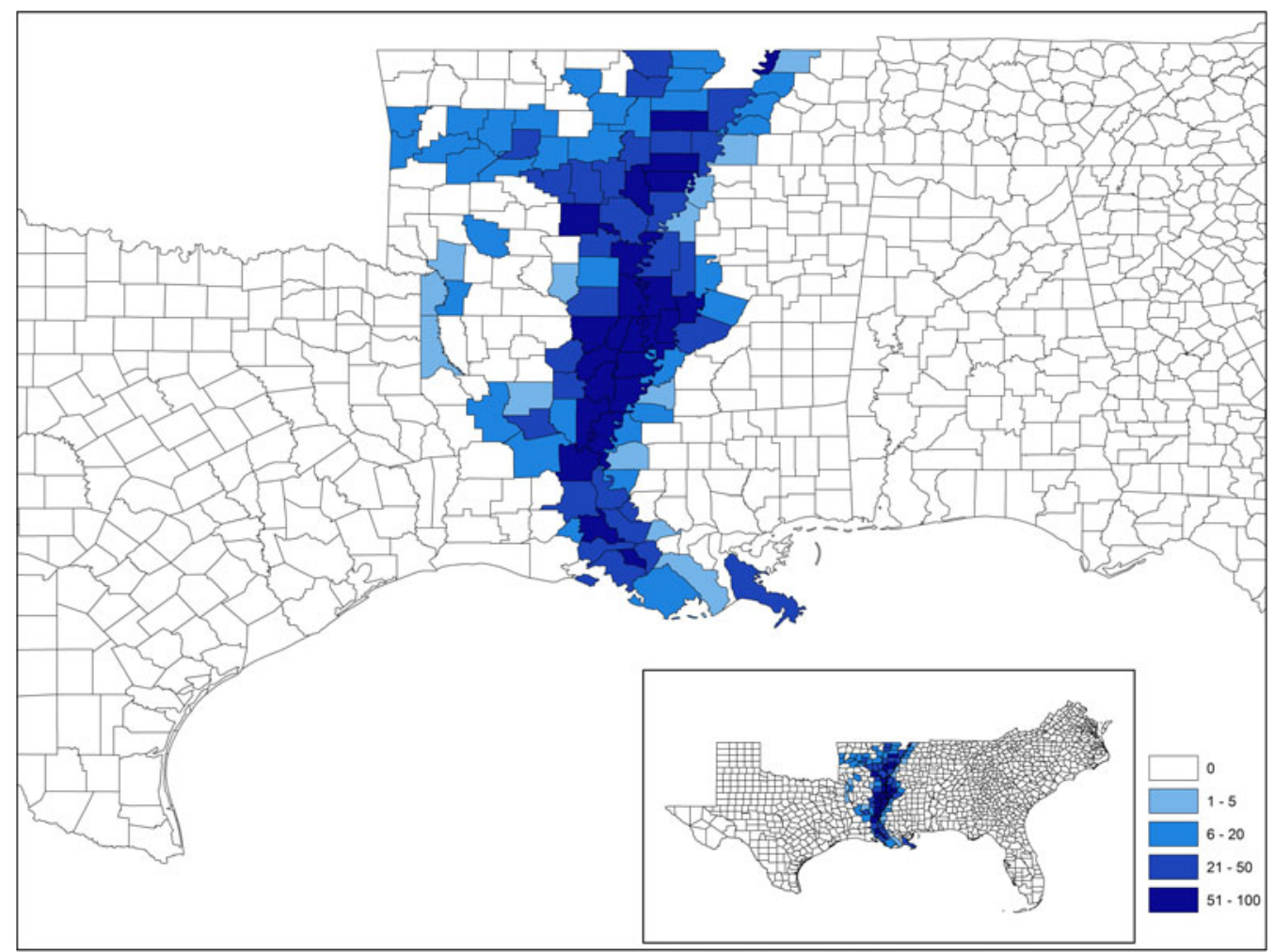

Figure 1. Flood severity by county during the Great Mississippi Flood of 1927. The percent of population affected by the Mississippi Flood, as reported by the Red Cross, across counties. More heavily flooded counties are shaded more darkly.

\section{The Great Mississippi Flood and the 1928 Presidential Election in the South}

The Great Mississippi Flood of 1927 remains one of the largest natural disasters in American history. In the spring of 1927, a period of unusually heavy rainfall combined with significant deforestation resulted in the bursting of levees and major flooding in the Mississippi river valley (Daniel 1977). The flood's devastation was unprecedented: over 26,000 square miles of land in 170 counties in Illinois, Kentucky, and-in particular-Tennessee, Arkansas, Mississippi, and Louisiana were flooded, and more than 750,000 people were forced to flee their homes (Spencer 1994; Kosar 2005). As Figure 1 illustrates, the flooding was particularly severe in Mississippi and Louisiana, with a considerable number of counties directly along the Mississippi River flooded entirely.

The flood was followed by a major relief operation organized by Republican President Calvin Coolidge's administration. ${ }^{4}$ The head of this operation was Herbert Hoover, then Secretary of Commerce and the GOP presidential nominee-to-be for 1928 (Barry 1997, 240). Under Hoover's leadership, more than 120,000 families across the South received Red Cross aid. Overall, the relief effort provided $\$ 32$ million to the affected areas (Kosar 2005; Daniel 1977), ${ }^{5}$ equivalent to $\$ 438$ million in 2015 dollars. Importantly, the distribution of relief funds was generally seen as efficient and fair-minded: Figure 2 illustrates the strong correlation between flood damage and flood relief at the county level. ${ }^{6}$ Compared to many other cases in the literature, this close correlation

4 At the time of the 1927 flood, no federal disaster response agency existed and the federal government cooperated with the Red Cross in cases of natural disasters. The Mississippi Flood relief effort was thus a Red Cross operation led by the Coolidge administration.

5 Relief efforts continued into the spring of 1928 when 71,000 people-predominantly in the South-received food relief. See "Red Cross Feeding 71,000 Mississippi Flood Victims," The Pittsburgh Courier, March 10, 1928.

6 Estimates of the population affected exceed $100 \%$ in several cases, likely as a result of measurement error. Our data on population affected is based on Red Cross estimates made during a large-scale emergency. Our data on population is interpolated from the decennial census, adding additional measurement error. 


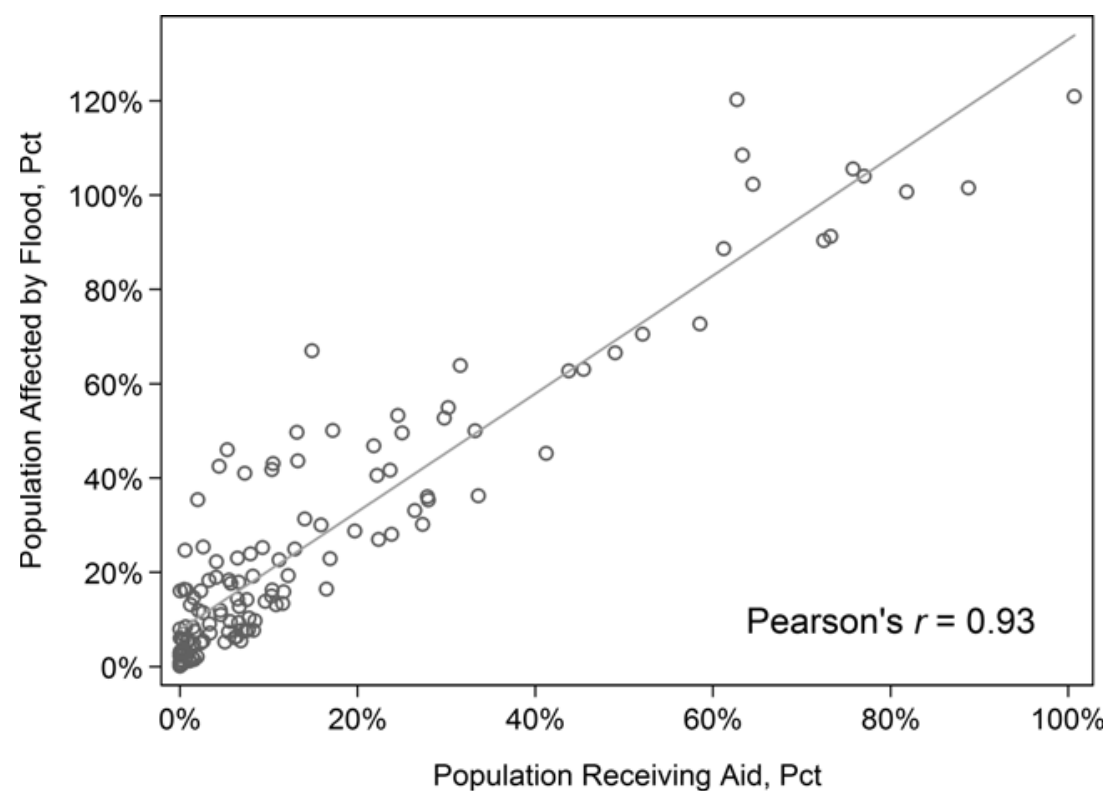

Figure 2. The correlation between flood severity and relief aid for treated counties in the US South $(n=98)$.

allows us to eliminate concerns regarding politically motivated relief distribution (Gallego 2012; Reeves 2011).

Hoover was also the public face of the relief operation, and made numerous site visits throughout the summer and fall of 1927. Newspapers and magazines reported on these visits, portraying Hoover as directly responsible for the relief efforts, ${ }^{7}$ and local officials expressed their appreciation for the aid they received. ${ }^{8}$ Hoover also referred to his role often throughout 1928 , and his campaign created a film, entitled "Herbert Hoover, Master of Emergencies," which showcased his humanitarian work during World War I and following the 1927 flood. ${ }^{9}$

The Mississippi Flood thus offers a good test to assess the net effect of disaster and relief on an important election in the pre-New Deal United States. The disaster itself was significant, affecting a swath of voters across the American South. Relief efforts were considerable as well, and relief aid appears to have been distributed according to need. Finally, the Republican standard-bearer in 1928, Hoover, was visibly in charge of operations, making the link between politician and relief distribution particularly strong in this case.

\section{Research Design}

We focus our analysis on southern counties, among which 98 of 1,007 in our data experienced some flooding. ${ }^{10}$ Our treatment variable is the percentage of individuals affected by the flood in each county $i$, as documented by the Red Cross in their post-disaster report. ${ }^{11}$ Since in this particular

7 See, e.g., "Hoover Calls Flood Lesson." New York Times, April 28, 1927; “Hoover to Return to Flooded Area," New York Times, June 17, 1927; "Hoover Heartens Land of Evangeline," New York Times, September 9, 1927.

8 For example, a New York Times article from January 1928 cites a local Democratic politician from Melville, Louisiana praising Hoover: "One of the local political leaders was asked by a correspondent how Melville would go if Hoover should be nominated [... " "If it happens and we catch any last-year's bird's nest around these parts voting against him, that voter won't vote no more," came the answer." ("The Sort of Man Herbert Hoover Is," New York Times, January 29, 1928).

9 See: "Text of Herbert Hoover's Address at Elizabethton, TENN.," Chicago Tribune, October 7, 1928; "Text of Herbert Hoover's Address At St. Louis," Chicago Tribune, November 3, 1928; "Campaign Movies Approved by Hoover," The Washington Post, May 8, 1928; "Hoover Movies Drew Many to Dunbar Center Oct. 10," The New York Amsterdam News, October 17, 1928.

10 We limit our analysis to southern counties because the bulk of the flooding occurred in the South and we wish to ensure comparability between treated and control units. All of the analysis we report is replicated in the Supplemental Appendix for the full, nationwide sample.

11 "The Mississippi Valley Flood Disaster of 1927: Official Report of Relief Operations of The American National Red Cross." The American National Red Cross, 1929. 
case disaster severity and aid are highly correlated (Figure 2), the measure of disaster damage includes the effect of both the natural disaster and subsequent relief efforts. In examining the 1927 Mississippi Flood, we can, therefore, assess the net effect by including only one measure in a statistical model. Because we expect the effect of flooding to vary with flood intensity, we bin this continuous treatment variable into a set of dummy variables representing varying levels of flood severity. We utilize a difference-in-differences approach, modeling the difference in Republican vote share between 1928 and 1924, $v_{1928}^{i}-v_{1924}^{i}$, as a function of a vector of covariates $\gamma$, and a vector of treatment dummies, $\delta$,

$$
v_{1928}^{i}-v_{1924}^{i}=B_{0}+\alpha \gamma_{i}+\theta \delta_{i}+\mu
$$

Note that we vary the number and construction of treatment dummies in several different specifications: we group all treated counties into a single treatment category; we split counties into three or five quantiles based on flood severity; and we also make subjective judgments regarding cutpoints in the treatment variable. The latter approach yields four categories, in which the percent of population impacted ranges from $0.1 \%$ to $5 \%, 5 \%$ to $20 \%, 20 \%$ to $50 \%$, and $50 \%$ and up, respectively.

\section{Results}

We report the primary results, focused on the coefficient $\theta$, in Figure 3. In each specification, we include the percent black from the 1920 US Census and a measure of county-level Protestantism, to control for the differential impact of Democratic presidential candidate Al Smith's Catholicism across counties with different religious leanings. ${ }^{12}$ Figure 3 plots coefficient estimates and 95\% confidence intervals for our treatment dummies across specifications, with more heavily flooded categories always appearing lower on the graph's $y$-axis.

In the aggregate, we find a large negative effect, -10.8 percentage points averaged across all flooded counties. When we split the treatment group by treatment intensity, we find strong negative effects among the lightly and moderately flooded counties. As flood severity increases to the highest levels, the treatment effect is diminished somewhat, and disappears in some cases. Our preferred model for judging treatment effect heterogeneity, which uses subjective cutpoints, is instructive: we estimate that the flood cost Hoover $13.1 \%, 10.2 \%$, and $15.5 \%$ of the two-party vote share in counties with low, medium-low, and medium-high levels of flooding and subsequent relief spending, constituting approximately three-quarters of flooded counties in the sample. However, in the most heavily hit counties, where $50 \%$ or more of the population was impacted, we cannot distinguish the flood's effect from the null. Similar results are obtained when we use "objective" approaches to binning treated units, as shown in Figure 3.

The models reported in Figure 3 mimic standard approaches in the literature but rely on the so-called "parallel trends" assumption. Time-varying heterogeneity between treated and control units, if it exists, can bias our treatment effect estimates. Our treatment and control groups are substantially different in terms of their black and Protestant populations: counties in the treatment group have a mean black population of $44.5 \%$ and a mean Protestant population of $27.9 \%$; the control group means in our southern sample are $26.8 \%$ and $37.2 \%$, respectively. Although difference-in-differences models account for time-invariant heterogeneity, they do not

12 Hoover performed much better in the South than previous Republican presidential candidates, largely due to southern Democratic opposition to the Democratic presidential candidate Al Smith. Smith was the first Catholic presidential candidate on a major-party ticket and he was opposed to Prohibition (Kelley 1963; Doherty 1947). On the other hand, Hoover did poorly in "black belt" counties where whites were a minority and voted for Smith out of fear Hoover would support anti-segregation policies (Key 1949, 5; Phillips 1969, 194-96). 


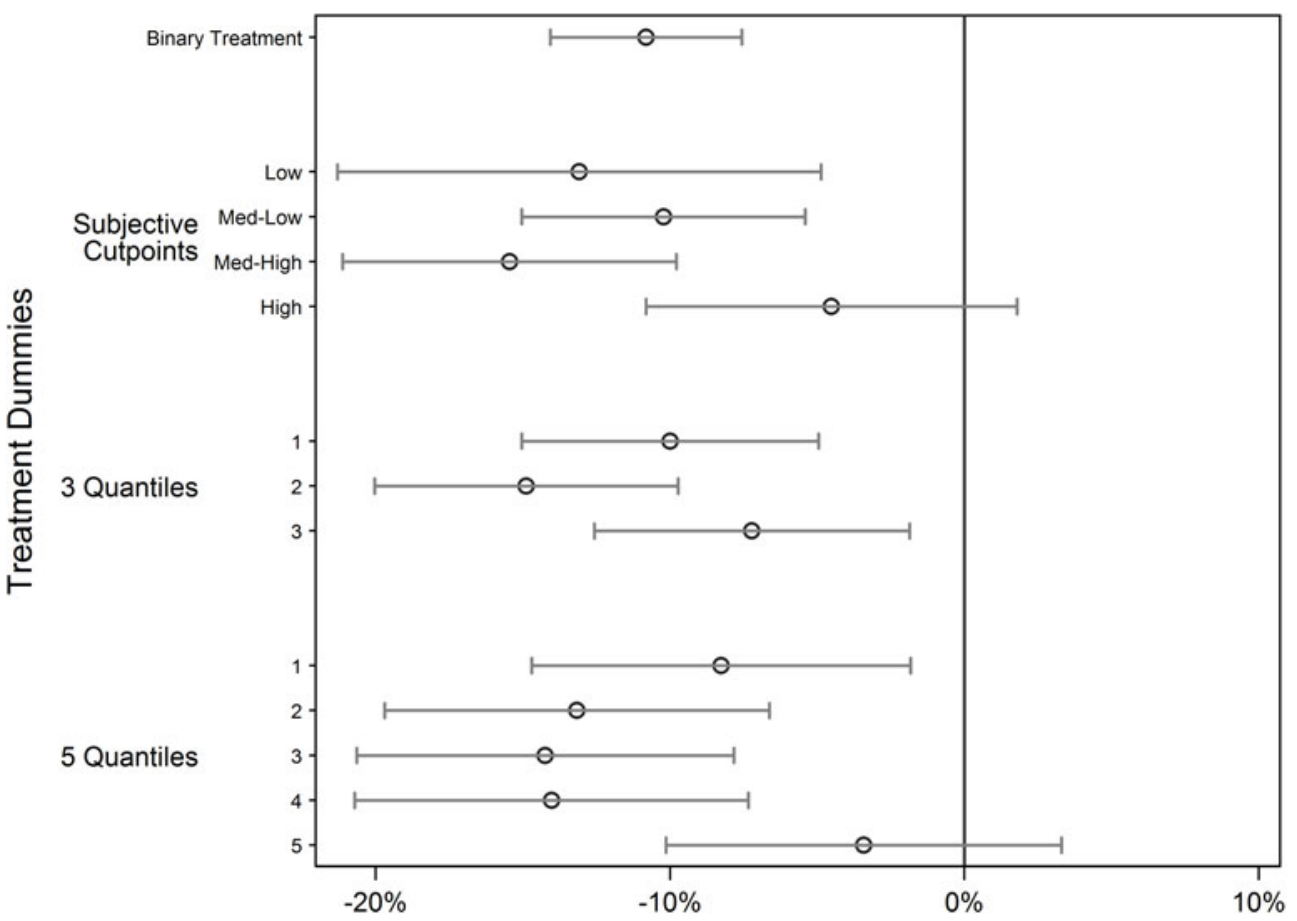

Figure 3. Effect estimates of flooding on Republican two-party vote share using different categories of flood severity. Coefficients and 95\% confidence intervals are reported from linear models $(n=980)$. Categorizations include a binary treatment (top), subjective cutpoints in severity $(0.1 \%-5 \%$; $5 \%-20 \%$; $20 \%-50 \%$; and $50 \%$ and up) and objective cutpoints based on quantiles.

account for heterogeneity that has disparate impact on outcomes across time. Both observed differences could produce bias toward a negative estimate that is specific to the 1928 election. ${ }^{13}$

While the regression models we estimate control explicitly for both of these factors, we address lingering concerns over such heterogeneity using the synthetic control method (Abadie et al. 2010). We employ this approach as a type of preprocessing, analogous to matching (Ho et al. 2007), in an effort to account for both time-invariant and time-varying heterogeneity. For each treated county $i$ in the data, we follow a two-step approach: first, we select the donor pool of control counties that will be used in the synthetic control unit. We limit the donor pool to the 100 counties most closely matched to county $i$ in terms of pretreatment vote share. ${ }^{14}$ Using this trimmed donor pool, we construct a synthetic control unit which most closely matches county $i$ in terms of pretreatment vote share over the period 1896-1924.

Under assumptions regarding match quality between a treated unit, $Y_{i t}^{I}$, and its synthetic control unit, $\sum_{j=1}^{100} w_{j} Y_{j t}$ (where $w$ is a vector of weights on the unit interval and $Y_{j t}$ is a vector of control units comprising the donor pool), the difference in outcomes in 1928 represents an unbiased unit-specific treatment effect (Abadie et al. 2010). Our estimand is the Sample Average Treatment Effect on the Treated (SATT), the mean of unit-specific treatment effects across 95 treated counties in the south.

Figure 4 summarizes our results and illustrates the causal effect of the Mississippi Flood among southern counties affected by the flood. The top panel plots Republican two-party vote share

13 Hoover's alleged soft stance on segregation would be particularly contentious among white voters in heavily black counties, who relied on Jim Crow laws to maintain political dominance. Meanwhile, Smith's Catholicism would benefit Hoover in more Protestant counties. If heavily black and lightly Protestant counties were more favorable to Smith, our results might overestimate the negative effect of flooding.

14 In alternative specifications, we vary the size of the donor pool. We also experiment with different trimming criteria, selecting control units that most closely match county $i$ with respect to the size of their black and Protestant populations. Treatment effect estimates vary across specifications but are uniformly negative and substantial. 
Republican Vote Share,

Treated and Synthetic Control Units
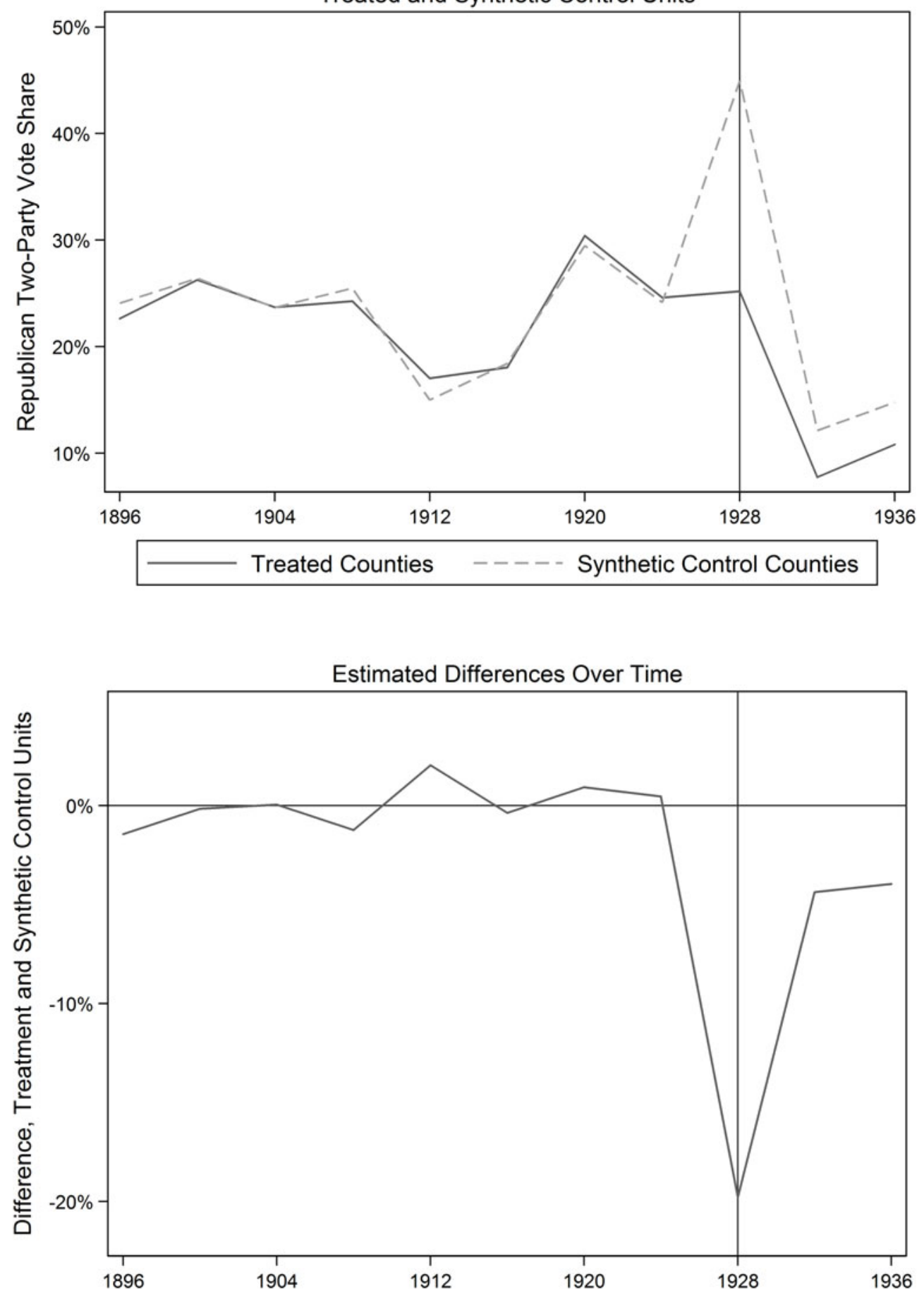

Figure 4. Estimate of the flood's effect using a synthetic control model. The gap between treated counties $(n=95)$ and their synthetic control units, from 1896 to 1936. Treatment occurred prior to the 1928 election. The gap in 1928, our estimate of the SATT, is -19.8 percentage points.

for treatment and control groups from 1896 to 1936, while the bottom panel plots the mean difference in vote share between the two groups over the same period. Our approach yields highquality matches on average over the period 1896 to 1924, before a precipitous drop in support for Hoover among flooded counties. The estimated difference in vote share in 1928 is -19.8 percentage points, reducing Hoover's vote share in flooded counties from $45 \%$ under the counterfactual to a 
mere $25.2 \%$ in reality. Unlike in the regression models reported previously, we do not observe meaningful treatment effect heterogeneity-our estimates range from a high of -16.1 to a low of $-24.2 \%$ across treatment levels and small changes across treatment levels are nonmonotonic. Treated counties at all levels of flood severity appear to have punished Hoover at the ballot box.

\section{Conclusion}

Do voters punish incumbents indiscriminately for misfortune caused by natural disasters? Or do voters rationally evaluate the quality of relief efforts? Several recent studies cast doubt on the theory of blind retrospection, favoring a view of the electorate as "attentive". But findings of voter attentiveness in the context of natural disasters have been drawn exclusively from cases in the post-New Deal era, while citizens' expectations of government action have arguably expanded in line with the expansion of the state. To the extent that voters judge leaders' performance relative to prevailing expectations, we expect reactions to natural disasters and subsequent relief efforts to vary across time and space.

We address external validity across time by studying the net effect of disaster and disaster relief in the case of the 1927 Mississippi Flood. Our analysis suggests that the effects of the flood on the 1928 presidential election were substantial and negative: we estimate that the flood cost Hoover 10.8 percentage points of the two-party vote share in affected counties. This estimate is not an artifact of modeling choice: in specifications that account for heterogeneity between treatment and control groups, our estimates of the flood's effect increase further. Nor is it a function of sample selection: as we show in the Supplemental Appendix, our results are robust across a nationwide sample that includes an additional 35 flooded counties outside the South. This result is particularly surprising, given how extensive these relief efforts were at the time, and how closely associated Hoover himself was to the operation. The results seem to confirm concerns about external validity based on the context in which governments operate.

These findings generally support Achen and Bartels' idea of blind retrospection, as the 1927 flood represents a hard case for the theory. But our results do not provide a full endorsement. While the net effect of the flood was broadly negative, we do not find that voters in harder-hit counties punished Hoover more. If anything, voters in counties that experienced less damage were more likely to punish Hoover-a distinction that runs counter to expectations of blind retrospection. Combined, our results raise two questions about retrospection in the wake of natural disasters-and the mechanisms by which it operates-that should guide future research. First, how does the extent to which voters are affected by a natural disaster shape their electoral behavior? Second, how do voters' expectations of government response affect their vote choice in the wake of a disaster? By engaging these questions, scholars may be able to better understand the logic-or lack thereof-behind voters' response to disaster and relief.

\section{Supplementary material}

For supplementary material accompanying this paper, please visit https://doi.org/10.1017/pan.2017.7.

\section{References}

Abadie, Alberto, Alexis Diamond, and Jens Hainmueller. 2010. Synthetic control methods for comparative case studies: Estimating the effect of California's tobacco control program. Journal of the American Statistical Association 105(490):493-505.

Abney, F. Glenn, and Larry B. Hill. 1966. Natural disasters as a political variable: The effect of a hurricane on an urban election. American Political Science Review 60(4):974-981.

Achen, Christopher H., and Larry M. Bartels. 2002. Blind Retrospection: Electoral Responses to Drought, Flu, and Shark Attacks. Paper prepared for presentation at the annual meeting of the American Political Science Association, Boston. 
Achen, Christopher H., and Larry M. Bartels. 2016. Democracy for realists: Why elections do not produce responsive government. Princeton, NJ: Princeton University Press.

Barry, John M. 1997. Rising tide: The Great Mississippi Flood of 1927 and how it changed America. New York: Simon \& Schuster.

Bechtel, Michael M., and Jens Hainmueller. 2011. How lasting is voter gratitude? An analysis of the short- and long-term electoral returns to beneficial policy. American Journal of Political Science 55(4):852-868.

Cole, Shawn, Andrew Healy, and Eric Werker. 2012. Do voters demand responsive governments? Evidence from Indian disaster relief. Journal of Development Economics 97(2):167-181.

Daniel, Pete. 1977. Deep'n as it come: The 1927 Mississippi river flood. New York: Oxford University Press.

Dauber, Michele Landis. 2013. The sympathetic state: Disaster relief and the origins of the American welfare state. Chicago: University of Chicago Press.

Doherty, Herbert J. 1947. Florida and the Presidential election of 1928. The Florida Historical Quarterly 26(2):174-186.

Fair, C. Christine, Patrick M. Kuhn, Neil Malhotra, and Jacob N. Shapiro. 2013. How natural disasters affect political attitudes and behavior: Evidence from the 2010-2011 Pakistani floods. Unpublished working paper.

Gallego, Jorge. 2012. Natural disasters and clientelism: The case of floods and landslides in Colombia. Unpublished working paper. Available at: http://papers.ssrn.com/sol3/paperscfm?abstract_id=2106312.

Gasper, John T., and Andrew Reeves. 2011. Make it rain? Retrospection and the attentive electorate in the context of natural disasters. American Journal of Political Science 55(2):340-355.

Healy, Andrew, and Neil Malhotra. 2009. Myopic voters and natural disaster policy. American Political Science Review 103(3):387-406.

Healy, Andrew, and Neil Malhotra. 2010. Random events, economic losses, and retrospective voting: Implications for democratic competence. Quarterly Journal of Political Science 5(2):193-208.

Heersink, Boris, Brenton D. Peterson, and Jeffery A. Jenkins. 2017. Disasters and elections: estimating the net effect of damage and relief in historical perspective, doi:107910/DVN/AKHHHF, Harvard Dataverse, V1, UNF:6:bcCeuvD3haeNx4alZXnrWw==.

Ho, Daniel E., Kosuke Imai, Gary King, and Elizabeth A. Stuart. 2007. Matching as nonparametric preprocessing for reducing model dependence in parametric causal inference. Political Analysis 15(3):199-236.

Kelley, Donald B. 1963. Deep south dilemma: The Mississippi press in the Presidential election of 1928. Journal of Mississippi History 25(1):63-92.

Key, V. O. Jr. 1949. Southern politics in state and nation. New York: A.A. Knopf.

Kosar, Kevin R. 2005. Disaster response and appointment of a recovery Czar: The executive branch's response to the flood of 1927. CRS Report for Congress (October 25, 2005).

Phillips, Kevin A. 1969. The emerging republican majority. New Rochelle, NY: Arlington House.

Reeves, Andrew. 2011. Political disaster: Unilateral powers, electoral incentives, and presidential disaster declarations. American Journal of Political Science 73(4):1142-1151.

Spencer, Robyn. 1994. Contested terrain: The Mississippi flood of 1927 and the struggle to control black labor. Journal of Negro History 79(2):170-181.

Sundquist, James L. 1983. Dynamics of the party system: Alignment and realignment of political parties in the United States, Revised Edition. Washington: Brookings Institution Press.

Tufte, Edward R. 1978. Political control of the economy. Princeton, NJ: Princeton University Press. 